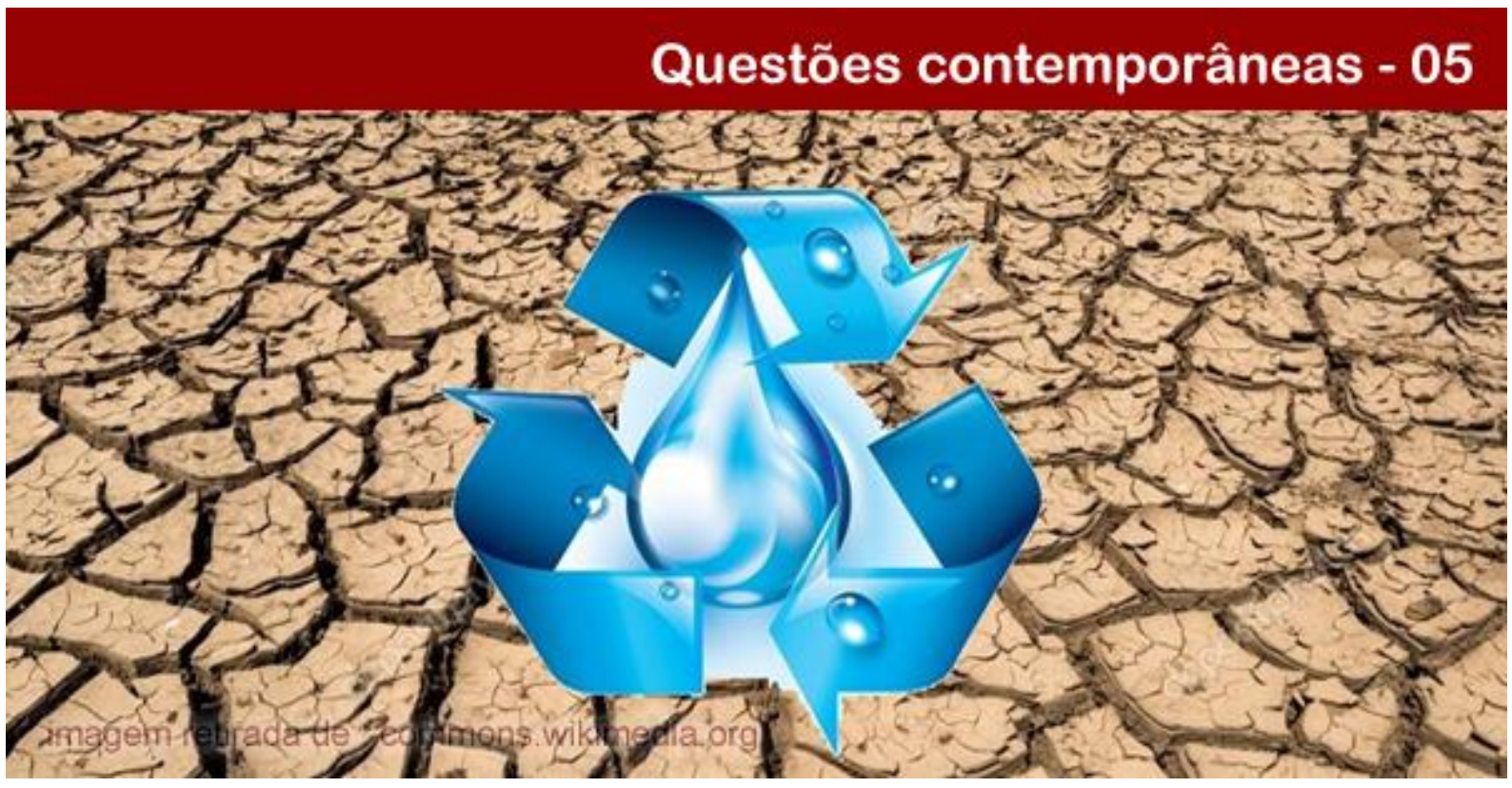

\title{
REÚSO dE ÁGUA E CONSTRUÇÃO DE CENÁRIOS FUTUROS: PERSPECTIVAS E DESAFIOS PARA REGIÕES SEMIÁRIDAS
}

Sandra Sereide Ferreira da Silva

Doutora em Recursos Naturais pelo Programa de Pós-Graduação em Recursos Naturais da Universidade Federal de Campina Grande (PPGRN/UFCG).E-mail: sandrasereide@yahoo.com.br.

\section{Vera Lúcia Antunes de Lima}

Professora do Departamento de Engenharia Agrícola e do Programa de Pós-Graduação em Recursos Naturais da Universidade Federal de Campina Grande (PPGRN/UFCG). E-mail: antuneslima@gmail.com.

Ângela Maria Cavalcanti Ramalho

Professora da Universidade Estadual da Paraíba (UEPB) e do Programa de Pós-Graduação em Recursos Naturais da Universidade Federal de Campina Grande (PPGRN/UFCG). E-mail: angelamcramalho@gmail.com.

\section{Allan Carlos Alves}

Professor do Departamento de Administração da Universidade Estadual da Paraíba (UEPB). E-mail: allan@ccsa.uepb.edu.br.

Resumo: A escassez da água em regiões áridas e semiáridas tem sido tema de debates, políticas e pesquisas com o objetivo principal de subsidiar as ações capazes de permitir o seu aproveitamento racional, permitindo a convivência da população com os períodos de seca ou reduzida precipitação. Assim, a escassez de água tem conduzido à implantação de projetos de desenvolvimento, que têm como desafio a busca de alternativas de convivência com a seca que conduzam a melhorias sociais. Com base nesse contexto, este estudo tem como objetivo propor a criação de um modelo de construção de cenários para viabilidade do reúso de água para ser utilizado como elemento mitigador das implicações da seca em regiões semiáridas. O modelo de construção de cenários é um importante instrumento de gerenciamento de recursos naturais, neste caso específico, recursos hídricos, pois permite envolver um grande número de participantes, tem a possibilidade de orientar o debate público para a construção estratégica coletiva de um futuro almejado, contribui para um eficaz processo de

\section{POLÊM!CA $\mid$ LABORE (}

Polêmica - Revista Eletrônica da Uerj - Rua São Francisco Xavier, 524, $1^{\circ}$ andar bloco D, sl.1001 • Tels.: +55 21 2334-4088 / 4087 • http://www.e-publicacoes.uerj.br/index.php/polemica/index http://www.labore.uerj.br • laboreuerj@yahoo.com.br 
aprendizagem organizacional no âmbito do Sistema Nacional de Gerenciamento de Recursos Hídricos visando um melhor entendimento, tanto dos aspectos ambientais quanto dos aspectos sociais e institucionais relacionados aos recursos hídricos no País, em especial, nas regiões semiáridas. Como se trabalham e convivem com a incerteza, os cenários procuram analisar e sistematizar as diversas probabilidades dos eventos e dos processos por meio da exploração dos pontos de mudança e das grandes tendências, de modo que as alternativas mais prováveis sejam antecipadas.

Palavras-chave: Recursos Hídricos. Reúso de Água. Regiões Semiáridas. Construção de Cenários.

\title{
WATER REUSE AND CONSTRUCTION OF FUTURE SCENARIOS: PERSPECTIVES AND CHALLENGES FOR SEMIARID REGIONS
}

\begin{abstract}
Water scarcity in arid and semi-arid regions has been the subject of debates, policies and research with the main objective of subsidizing actions capable of allowing their rational use, allowing the population to coexist with periods of drought or reduced precipitation. Thus, water scarcity has led to the implementation of development projects, which challenge the search for alternatives to coexistence with drought that lead to social improvements. Based on this context, this study aims to propose the creation of a model for the construction of scenarios for the feasibility of water reuse to be used as a mitigating element of the drought implications in semiarid regions. The scenario building model is an important tool for managing natural resources, in this specific case, water resources, since it allows a large number of participants to be involved, it has the possibility of guiding the public debate towards the collective strategic construction of a desired future, contributes to an effective organizational learning process within the National Water Resources Management System aiming at a better understanding of both the environmental aspects and the social and institutional aspects related to the water resources in the Country, especially in the semi-arid regions. As they work and coexist with uncertainty, the scenarios seek to analyze and systematize the various probabilities of events and processes by exploring the points of change and the major trends, so that the most likely alternatives are anticipated.
\end{abstract}

Keywords: Water Resources. Water reuse. Semi-Arid Regions. Construction of Scenarios.

\section{Introdução}

É notório que a água é um recurso natural escasso e cuja disponibilidade tem sido intensamente limitada, especialmente em regiões áridas e semiáridas. As projeções e tendências traduzem sérios riscos de conflitos e vulnerabilidades cada vez mais complexos. Toda e qualquer estratégia de uso e gestão deve estar focada nos conceitos mínimos de sustentabilidade, considerando também as possibilidades de utilização de águas servidas e residuárias como alternativas potenciais de minimização do impacto decorrente da escassez já identificada nos diferentes setores de produção. A importância do uso eficiente, obviamente, varia de região para região e de acordo com a época. Tratando-se do semiárido a situação se agrava, sendo basilar que a concepção do uso dos recursos hídricos seja fundamentada no conhecimento cada vez mais aprofundado e abrangente, de forma a assegurar a melhor partição entre as atividades de demanda e produção.

A escassez da água em regiões áridas e semiáridas tem sido tema de debates, políticas e pesquisas com o objetivo principal de subsidiar as ações capazes de permitir o seu aproveitamento racional, permitindo a convivência da população com os períodos de seca ou

\section{POLÊM!CA | LABORE (3.}

Polêmica - Revista Eletrônica da Uerj - Rua São Francisco Xavier, 524, $1^{\circ}$ andar bloco D, sl.1001 • Tels.: +55 21 2334-4088/4087 • http://www.e-publicacoes.uerj.br/index.php/polemica/index http://www.labore.uerj.br • laboreuerj@yahoo.com.br 
reduzida precipitação. Em virtude dessa situação, a escassez de água tem conduzido a implantação de projetos de desenvolvimento, que têm como desafio a busca de alternativas de convivência com a seca que conduzam a melhorias sociais. Neste enfoque, o reúso agrícola planejado de água mostra-se como uma oportunidade de valorização da atividade agrícola nessas regiões.

Conforme enfatiza Asano (2002), o reúso planejado de água é uma prática internacionalmente estabelecida em todos os continentes e tem sido largamente utilizado, de forma segura e controlada, em diversos países, inclusive para aumentar o suprimento de água potável, como ocorre na Namíbia, desde 1968. Em Israel, o reúso de águas servidas é uma prioridade nacional (FRIEDLER, 2001). No continente europeu, em países como França, Itália, Portugal, Espanha e Grécia, águas servidas tratadas são utilizadas na agricultura irrigada, dentre diversos outros usos não potáveis (MONTE, 2007). Nos Estados Unidos, o reúso é praticado em larga escala (USEPA, 2004). Na Austrália, o Programa Nacional de Reúso de Água tem avançado na consolidação adequada do reúso como prática de conservação da água (DILLON, 2000).

Pode-se afirmar que a tendência atual, verificada por instituições de gestão das águas na Europa, em Israel e na Austrália, é considerar o reúso como componente da gestão integrada dos recursos hídricos e do desenvolvimento sustentável, não apenas em regiões com problemas de escassez de água, mas também em regiões densamente povoadas, onde a degradação da qualidade das águas de superfície e subterrâneas tem levado a situações de escassez (FRIEDLER, 2001; HURLIMANN, 2008; SALGOT et al., 2006). Mesmo em regiões onde existia abundância, o nível de poluição das águas tem aumentado os custos com tratamento e inviabilizado alguns mananciais. O reúso se apresenta como alternativa para minimizar a pressão de demanda sobre os mananciais, devendo ser inserido nos primeiros estágios do planejamento de recursos hídricos (URKIAGA et al., 2008). O entendimento de que o reúso de água é um importante componente da gestão de recursos hídricos é explicitado na literatura do tema por diversos especialistas do assunto, mas esta prática ainda é recente no Brasil e sua regulamentação ainda é incompleta, nas escalas nacional e regional.

Entretanto, advirta-se que a percepção social acerca do reúso é um fator determinante para a sua aceitação e viabilidade, que está diretamente ligada ao grau de confiança da população nas instituições responsáveis pelo seu gerenciamento e a outras questões

\section{POLÊM!CA $\mid$ LABORE}

Polêmica - Revista Eletrônica da Uerj - Rua São Francisco Xavier, 524, $1^{\circ}$ andar bloco D, sl.1001 • Tels.: +55 21 2334-4088/4087 • http://www.e-publicacoes.uerj.br/index.php/polemica/index http://www.labore.uerj.br • laboreuerj@yahoo.com.br 
relacionadas à maneira como projetos são apresentados e percebidos pela sociedade: a boa comunicação entre os setores envolvidos é fundamental. Porém, alerte-se que o reúso, não planejado, ocorre sistematicamente como uma determinação de condições socioeconômicas e ambientais nas periferias das grandes cidades brasileiras, notadamente, na Região Nordeste. Para Hespanhol (2008), a percepção dessas comunidades a respeito do reúso está pautada no nível de informação que tenham acesso, à confiança nos interlocutores aos quais estejam apresentando o projeto, à forma como se relacionam com os mananciais hídricos locais e à sua percepção sobre as diversas implicações da seca ao ser humano e ao meio ambiente.

No campo das possibilidades, a metodologia de construção de cenários apresenta-se de suma importância para o gerenciamento dos recursos hídricos, pois permite envolver um grande número de participantes, orienta o debate público para a construção estratégica coletiva de um futuro almejado e contribui para um eficaz processo de aprendizagem organizacional no âmbito do Sistema Nacional de Gerenciamento de Recursos Hídricos. Isso tudo possibilita um melhor entendimento, tanto dos aspectos ambientais quanto dos aspectos sociais e institucionais relacionados aos recursos hídricos no País, em especial, regiões semiáridas.

Em razão dessa constatação e das considerações pontuadas, notadamente no que concerne à implementação de um processo de reúso de água não provocativo de externalidades negativas ao meio ambiente, tendo como pressuposto princípios e critérios de sustentabilidade e desenvolvimento sustentável numa visão de longo prazo, configura-se o seguinte problema de pesquisa: Qual metodologia pode ser utilizada para a construção de cenários para viabilidade do uso de água residuária como elemento mitigador das implicações da seca em regiões semiáridas?

A fim de responder a este questionamento, este estudo tem como objetivo propor a criação de uma metodologia de construção de cenário para viabilidade do reúso de água para ser utilizado como elemento mitigador das implicações da seca em regiões semiáridas.

\section{Questão hídrica e reúso da água}

Desde 2012, alguns Estados brasileiros, a exemplo dos estados nordestinos, são assolados por uma inclemente seca, que impõe restrições graves à população, sobretudo as necessidades do chamado "mínimo existencial"; e o acesso à água é a principal delas. Tudo

\section{POLÊM!CA $\mid$ LABORE}

Polêmica - Revista Eletrônica da Uerj - Rua São Francisco Xavier, 524, $1^{\circ}$ andar bloco D, sl.1001 • Tels.: +55 21 2334-4088 / 4087 • http://www.e-publicacoes.uerj.br/index.php/polemica/index http://www.labore.uerj.br • laboreuerj@yahoo.com.br 
isso compõe um quadro que se agravou nos últimos anos, com o impacto das mudanças climáticas. Esse cenário de vulnerabilidade hídrica é atestado em pesquisas e relatórios divulgados pela Agência Nacional das Águas - ANA; e, embora a gestão dos recursos hídricos objetive sanar problemas seculares, o quadro piorou nos últimos anos, não só pela ausência de efetividade social de dispositivos expressos na própria Lei dos Recursos Hídricos, mas também em razão de um novo fator que, hoje, deve ser considerado: as mudanças climáticas. O Painel Intergovernamental sobre Mudança Climática - IPCC, órgão da ONU, divulgou em Yokohama, Japão, em março de 2014, resultados da pesquisa sobre a incidência e o agravamento das mudanças climáticas ao redor do planeta e de como elas afetarão a vida dos seres humanos nos próximos anos.

Os múltiplos usos da água na agricultura, em um passado recente, não representavam tantos riscos em relação à segurança hídrica, mas, hoje, com o aumento progressivo da produção de alimentos em razão da demanda mundial e do uso intensivo de água na agricultura, o que se vê é a degradação da qualidade da água superficial e subterrânea. Além disso, "a eutrofização de lagos, represas e rios é uma das consequências dos usos excessivos de fertilizantes na agricultura, os quais, combinados com alterações de drenagem, podem aumentar excessivamente os índices de estado trófico" (TUNDISI, 2008). Para um dos maiores estudiosos do tema no Brasil, o geógrafo Wagner Ribeiro Costa, o principal fator que agrava a escassez de água doce na Terra é o seu uso na esfera privada de maneira irresponsável, com fins de acumulação de capital; ele traz inclusive; dados sobre o aumento exponencial, por exemplo, do uso da água na agricultura: “o consumo, que era de $2.574 \mathrm{~km}^{3}$ por ano, em 1970, foi para $3.940 \mathrm{~km}^{3}$, em 2000. A área irrigada passou de 160 milhões de hectares para 275 milhões. O incremento de novas terras à produção foi de $41 \%$, enquanto a demanda por água aumentou 53\% em 30 anos" (RIBEIRO, 2013). Contudo, o acirramento da crise da água no início do século XXI não ocorreu só em razão de um fator; trata-se de uma soma de fatores próprios de uma sociedade que, a partir do século XIX, deixou de ser eminentemente agrária e tornou-se urbana. A "explosão" da urbanização está ligada a diversos fatores, dentre os quais a vulnerabilidade hídrica de várias regiões do globo, pois a ação do homem sobre o solo pode produzir alterações substanciais nos processos hidrológicos terrestres, como a redução ou o aumento da vazão média, máxima e mínima de uma bacia hidrográfica e a alteração da qualidade da água. O impacto do desenvolvimento urbano se

\section{POLÊM!CA $\mid$ LABORE}

Polêmica - Revista Eletrônica da Uerj - Rua São Francisco Xavier, 524, $1^{\circ}$ andar bloco D, sl.1001 • Tels.: +55 21 2334-4088/4087 • http://www.e-publicacoes.uerj.br/index.php/polemica/index http://www.labore.uerj.br • laboreuerj@yahoo.com.br 
constitui em um dos efeitos significativos sobre o ambiente, criando condições extremamente desfavoráveis sobre os rios, na vizinhança dos centros urbanos.

Adentrando-se nesse contexto e tomando como base a perspectiva de que o reúso de água deve ser considerado como parte de uma atividade mais abrangente, que é o uso racional ou eficiente da água, o qual compreende também o controle de perdas e desperdícios, e a minimização da produção de efluentes e do consumo de água; os esgotos tratados têm um papel fundamental no planejamento e na gestão sustentável dos recursos hídricos como um substituto para o uso de águas destinadas a fins agrícolas, florestais, industriais, urbanos e ambientais.

Ao liberar as fontes de água de boa qualidade para abastecimento público e outros usos prioritários, o uso de esgotos contribui para a conservação dos recursos e acrescenta uma dimensão econômica ao planejamento dos recursos hídricos. O reúso minimiza a demanda sobre os mananciais de água devido à substituição da água potável por uma água de qualidade inferior. Essa prática, atualmente muito discutida, posta em evidência e já utilizada em alguns países é baseada no conceito de substituição de mananciais. Tal substituição é possível em função da qualidade requerida para um uso específico (CETESB, 2016). Assim, podem-se poupar grandes volumes de água potável através do reúso com a utilização de água de qualidade inferior (geralmente efluentes pós-tratados) para atendimento das finalidades que podem prescindir desse recurso dentro dos padrões de potabilidade.

Com o objetivo de estabelecer um pacto nacional para a definição de diretrizes e políticas públicas direcionadas para a melhoria da oferta de água, em quantidade e qualidade, para as diversas atividades humanas, sem esquecer o papel essencial que os recursos hídricos desempenham na existência (e reprodução) dos ecossistemas onde estão inseridos, aprovouse, em 2006, o Plano Nacional de Recursos Hídricos (PNRH). Dentre outras atribuições, o PNRH visa propiciar o gerenciamento das demandas, considerando a água um elemento estruturante para a implantação de políticas setoriais voltadas ao desenvolvimento sustentável e à inclusão social.

Contudo, advirta-se que a concepção de gestão de recursos hídricos tem se transformado desde as décadas de 1980 e 1990. Na esfera dos recursos hídricos, o Estado Planejador-Investidor com decisão centralizada e objetivando o crescimento econômico transforma-se em um Estado mediador de conflitos e regulador, que usa descentralização, a

\section{POLÊM!CA $\mid$ LABORE}

Polêmica - Revista Eletrônica da Uerj - Rua São Francisco Xavier, 524, $1^{\circ}$ andar bloco D, sl.1001 • Tels.: +55 21 2334-4088/4087 • http://www.e-publicacoes.uerj.br/index.php/polemica/index http://www.labore.uerj.br • laboreuerj@yahoo.com.br 
participação pública e uma visão integrada como método e o desenvolvimento sustentável, com o seu tripé: equidade social, eficiência econômica, e sustentabilidade ambiental, como objetivo finalístico. Nesse sentido, as ações de planejamento e investimento ficaram submetidas ao sistema de mediação de conflitos.

A esta mudança na função social da gestão de águas, soma-se uma ampliação nas dimensões da gestão de recursos hídricos que expande o horizonte da gestão da oferta (por exemplo, incorporando novos mananciais dessalinizando água do mar ou fazendo reúso) e constrói novas dimensões na gestão da demanda e na gestão de conflitos pelo uso da água. A este movimento soma-se outro, denominado no Plano por Tensão da Sustentabilidade, que consiste no conflito entre desenvolvimento (entendido como crescimento econômico) e meio ambiente. Esta tensão estabelece os limites entre o sistema de recursos hídricos (água para nós - água enquanto insumo econômico) e o sistema ambiental (água em si - água essencial aos ecossistemas); assim como assinala a dimensão da sustentabilidade ambiental no gerenciamento de recursos contemporâneo.

Afluente a este movimento, o planejamento de recursos hídricos, transforma-se; não segue mais o modelo de planejamento racional clássico. O modelo adotado pelo planejamento de recursos hídricos brasileiro tem por base a Lei $n^{\circ}$ 9.433, de 1997 - Política Nacional de Recursos Hídricos, um modelo de planejamento político (BRASIL, 1997). Pode-se afirmar que o Plano, no contexto da Lei, é um espaço de reflexão com vistas à identificação de soluções de compromisso para os conflitos potenciais ou manifestos, inerentes ao gerenciamento de recursos hídricos.

Mediante essa concepção, permite-se assegurar que no planejamento de recursos hídricos, o uso de cenários prováveis e exploratórios ainda é uma novidade, especialmente em se tratando de sua aplicação no âmbito de bacias hidrográficas. A sua aplicação tem sido mais comum em estudos de âmbitos geográficos e setoriais mais abrangentes. Contudo, no plano internacional, há duas experiências de estudos prospectivos na área de recursos hídricos que merecem destaque. A primeira foi o desenvolvimento de uma Visão Mundial da Água (WORLD WATER COUNCIL, 2000) pelo Conselho Mundial da Água, que envolveu mais de 15 mil pessoas em todo o mundo, objetivando explicitar aspirações e estratégias de desenvolvimento de ações práticas para o uso sustentável e o manejo dos recursos hídricos.

\section{POLÊM!CA $\mid$ LABORE}

Polêmica - Revista Eletrônica da Uerj - Rua São Francisco Xavier, 524, $1^{\circ}$ andar bloco D, sl.1001 • Tels.: +55 21 2334-4088/4087 • http://www.e-publicacoes.uerj.br/index.php/polemica/index http://www.labore.uerj.br • laboreuerj@yahoo.com.br 
Foram elaborados cenários prospectivos qualitativos, com a quantificação de algumas variáveis. A Visão Mundial da Água inclui contribuições de profissionais e atores que desenvolveram visões regionais integradas em mais de quinze regiões do mundo. Os resultados foram apresentados pela Comissão Mundial de Água para o Século XXI, no segundo Fórum Mundial da Água, realizado em 2000, na Holanda. A segunda experiência, de âmbito global, que adotou a cenarização prospectiva, enfocando a temática ambiental e de recursos hídricos, foi realizada em 2003 pelo Programa das Nações Unidas para o Meio Ambiente (PNUMA). A iniciativa fez parte da série Global Environment Outlook (PNUMA, 2004) em sua terceira edição. Foram desenvolvidos cenários qualitativos (narrativos) e realizadas quantificações, com a utilização de alguns modelos. O exercício contou com a participação de aproximadamente mil pessoas e quarenta instituições em todo o mundo.

No Brasil nunca ocorreram semelhantes experiências antes do PNRH, provavelmente pelo caráter conservador das instituições estatais e pela pouca divulgação que ainda possuíam as técnicas de construção de cenários no país. No âmbito nacional, o uso de cenários exploratórios é muito recente. Não tem mais que trinta anos. No caso de recursos hídricos reúso de água - é inédito. Advirta-se que a importância do reúso de água apresenta-se como uma estratégia contributiva para o eficaz gerenciamento dos recursos hídricos em regiões semiáridas. Neste cenário de escassez dos recursos hídricos, a disputa pelo uso da água, mesmo sendo um bem de domínio público, conforme Vargas (2005) virou um tabuleiro de negócios com muitos interesses. É nesse campo, de acordo com Lima (2009), que emana uma discussão importante e salutar a respeito de novas possibilidades para o aproveitamento dos efluentes domésticos e industriais que podem ser usados como fonte alternativa para ampliar a demanda hídrica e diminuir a pressão sobre os mananciais primários.

\section{Metodologia para construção de cenários para viabilidade do reúso de água em regiões semiáridas}

A construção dos cenários, para a metodologia proposta, origina-se de um processo que percorre sete etapas: os estudos prospectivos constituem parte importante do processo de planejamento, na medida em que oferecem uma orientação para as tomadas de decisões acerca de iniciativas e ações para a construção do futuro almejado pela sociedade, governo e pelas empresas.

\section{POLÊM!CA | LABORE}

Polêmica - Revista Eletrônica da Uerj - Rua São Francisco Xavier, 524, $1^{\circ}$ andar bloco D, sl.1001 • Tels.: +55 21 2334-4088/4087 • http://www.e-publicacoes.uerj.br/index.php/polemica/index http://www.labore.uerj.br • laboreuerj@yahoo.com.br 
Dentre os estudos prospectivos, a técnica de cenários tem se firmado como um dos principais recursos metodológicos, tendo sido incorporada aos processos de planejamento estratégico tanto empresarial quanto sócio governamental. Os estudos de cenários recorrem, normalmente, a um conjunto de técnicas e processos de sistematização, de organização das informações, de hipóteses como forma de análise das probabilidades de comportamentos futuros, de organização, de teste da criatividade e das percepções subjetivas. Existe, evidentemente, um grande e diversificado conjunto de técnicas que serve para realizar os diversos estágios do processo de construção de cenários. Ressalve-se para a definição de Godet (1996) que afirma que o futuro é uma construção social, na qual os atores sociais devem ocupar uma posição central na construção desses cenários. Diante desse enfoque, a construção dos cenários para viabilidade do uso de água residuária como elemento mitigador das implicações da seca em regiões semiáridas, origina-se de um processo que percorre sete etapas elencadas no Quadro 1, a saber:

Quadro - 1: Principais etapas do modelo para construção de cenários para viabilidade do uso de água residuária como elemento mitigador das implicações da seca em regiões semiáridas

\begin{tabular}{|c|c|}
\hline $\begin{array}{c}\text { ETAPAS DA } \\
\text { METODOLOGIA DE } \\
\text { CONSTRUÇÃO DE } \\
\text { CENÁRIOS PARA REÚSO DE } \\
\text { ÁGUA EM REGIÕES } \\
\text { SEMIÁRIDAS }\end{array}$ & DESCRIÇÃO - SÍNTESE DE CADA ETAPA DA METODOLOGIA \\
\hline $\begin{array}{l}\text { Definição do escopo do objeto } \\
\text { de cenarização }\end{array}$ & $\begin{array}{l}\text { Na estruturação do escopo do objeto de cenarização, prevê-se o horizonte de } \\
\text { 2030, correspondendo, portanto, a treze anos. O objeto da cenarização, por } \\
\text { sua vez, será definido como sendo o conjunto das variáveis (dimensões e } \\
\text { indicadores a serem definidos) e atores que fazem parte do Sistema Nacional } \\
\text { de Recursos Hídricos. Por sua vez, a lógica do sistema consistirá em } \\
\text { assegurar: } \\
\text { 1. O uso múltiplo das águas residuárias pelos diversos } \\
\text { usuários, com prioridade para o uso agrícola; } \\
\text { 2. A qualidade das águas, em conformidade com os seus } \\
\text { diversos usos; } \\
\text { 3. A quantidade necessária das águas, para responder às } \\
\text { diversas demandas, segundo os objetivos nacionais } \\
\text { (segundo a Constituição de 1988, são: erradicar a } \\
\text { pobreza, reduzir a desigualdade e assegurar o bem-estar } \\
\text { social para todos os membros do corpo da Nação) e, por } \\
\text { fim; } \\
\text { 4. A sustentabilidade ambiental, com o objetivo de assegurar a } \\
\text { reprodução dos diversos ecossistemas. }\end{array}$ \\
\hline & $\begin{array}{l}\text { Ia a definição das variáveis (dimensões e indicadores) relevantes para o } \\
\text { tema de recursos hídricos - Reúso de Água - deve ser proposto com o }\end{array}$ \\
\hline
\end{tabular}

\section{POLÊM!CA $\mid$ LABORE}

Polêmica - Revista Eletrônica da Uerj - Rua São Francisco Xavier, 524, $1^{\circ}$ andar bloco D, sl.1001 • Tels.: +55 21 2334-4088 / 4087 • http://www.e-publicacoes.uerj.br/index.php/polemica/index http://www.labore.uerj.br • laboreuerj@yahoo.com.br 


\begin{tabular}{|c|c|}
\hline Análise estrutural & $\begin{array}{l}\text { apoio de uma equipe técnica com conhecimento no tema um conjunto inicial } \\
\text { de variáveis. Após debates sobre sua viabilidade, a quantidade de variáveis } \\
\text { poderá ser redefinida e reagrupada. Para tanto, deve ser estabelecido prazo } \\
\text { para ocorrer tais debates com os vários atores sociais e institucionais } \\
\text { envolvidos nesta proposta. Finalizada essa etapa ocorrerá a análise estrutural. } \\
\text { Essa análise objetiva identificar e classificar as variáveis e o seu jogo de } \\
\text { mútuas influências, visando identificar quais as incertezas críticas, ou seja, as } \\
\text { variáveis de maior grau de incerteza e mais capacidade de influência sobre o } \\
\text { sistema como um todo. A análise estrutural classifica as variáveis em quatro } \\
\text { tipos, a saber: } \\
\text { a) motrizes - responsáveis principais pela evolução do sistema, por } \\
\text { sua alta capacidade de influência; } \\
\text { b) de ligação - que intermedeiam o jogo de influência no âmbito do } \\
\text { sistema; } \\
\text { c) de resultado - receptoras principais das influências do sistema, } \\
\text { servindo de indicadoras de sua evolução, e; } \\
\text { d) autônomas - ou seja, com baixa relação com o sistema, tendo } \\
\text { relativa independência em relação a outras variáveis. } \\
\text { A ferramenta utilizada na análise estrutural será a matriz de análise de } \\
\text { variáveis, duas a duas, denominada URCA (unidirecional, reversa, circular e } \\
\text { ausente de interferências, conforme Marques, 2004). O resultado será a } \\
\text { definição de um conjunto "x" de incertezas críticas para os recursos hídricos } \\
\text { - reúso de água na agricultura - semiárido paraibano, tomados como insumo } \\
\text { para a etapa seguinte, a de investigação morfológica. }\end{array}$ \\
\hline Investigação Morfológica & $\begin{array}{l}\text { A investigação morfológica consistirá na combinação lógica racional dos } \\
\text { estados possíveis das incertezas críticas selecionadas, ou seja, as suas } \\
\text { expressões concretas mais prováveis, levando em consideração a natureza e a } \\
\text { provável evolução de cada uma delas. A partir disso, serão construídas as } \\
\text { combinações mais prováveis segundo as percepções dos participantes. } \\
\text { Da aplicação da investigação morfológica resultarão os tipos de cenários } \\
\text { (cenário otimista, normal e pessimista), os quais serão submetidos a testes de } \\
\text { plausibilidade e consistência. }\end{array}$ \\
\hline $\begin{array}{l}\text { Teste de plausibilidade política } \\
\text { e consistência dos cenários } \\
\text { gerados }\end{array}$ & $\begin{array}{l}\text { Esse teste consistirá no cruzamento dos interesses dos atores sociais e } \\
\text { institucionais em relação aos de cenários construídos. Ele permitirá que se } \\
\text { identifiquem quais os cenários com maior ou menor promoção entre os atores } \\
\text { mais relevantes. Estes, por sua vez, serão selecionados a partir da lista dos } \\
\text { atores sinalizados nas reuniões realizadas. A partir da realização do teste de } \\
\text { plausibilidade, ocorrerá a identificação de cenários com maior ou menor } \\
\text { apoio dos atores e, portanto, maior ou menor plausibilidade, caso os atores } \\
\text { mantenham suas posições ao longo do período de cenarização. Na escolha } \\
\text { deverão prevalecer alguns critérios tais como: } \\
\text { a) selecionar os cenários extremos, ou seja, aquele com maior } \\
\text { apoio e outro, com menor apoio, já que uma das funções dos cenários é } \\
\text { abarcar o maior espaço de futuros plausíveis; } \\
\text { b) guardar os cenários com maior distinção entre eles, pois } \\
\text { cenários muito similares não servem, pois apenas acumulam dúvidas no } \\
\text { processo de monitoramento. }\end{array}$ \\
\hline $\begin{array}{l}\text { Desenvolvimento dos cenários } \\
\text { selecionados }\end{array}$ & $\begin{array}{l}\text { Cenários selecionados são objetos de desenvolvimento, ou seja, descrição } \\
\text { pormenorizada, segundo uma matriz previamente construída na qual as } \\
\text { principais variáveis e dimensões do escopo do objeto serão contemplados. } \\
\text { Em alguns casos poderá ser adotado o sistema de descrição das etapas da } \\
\text { trajetória do cenário, com segmentação do período selecionado. }\end{array}$ \\
\hline Comparação e quantificação dos & O sexto passo da metodologia adotada consistirá na comparação e \\
\hline
\end{tabular}

\section{POLÊM!CA LABORE (?)}

Polêmica - Revista Eletrônica da Uerj - Rua São Francisco Xavier, 524, $1^{\circ}$ andar bloco D, sl.1001 • Tels.: +55 21 2334-4088 / 4087 • http://www.e-publicacoes.uerj.br/index.php/polemica/index http://www.labore.uerj.br • laboreuerj@yahoo.com.br 


\begin{tabular}{|c|c|}
\hline cenários finais & quantificação simplificada dos cenários finais selecionados. \\
\hline $\begin{array}{llll}\text { Identificação da base } & \text { de } \\
\text { sustentação da } & \text { estratégia } & \text { do } \\
\text { plano } & & & \end{array}$ & $\begin{array}{l}\text { Elaborados os cenários, iniciar-se-á a definição da base sobre a qual o plano } \\
\text { irá repousar. Há três procedimentos usualmente utilizados, a saber: } \\
\text { a) Escolhe-se o cenário julgado mais interessante do ponto de } \\
\text { vista dos construtores ou o mais provável; } \\
\text { b) Constrói-se uma visão de futuro, ou então; } \\
\text { c) Define-se o campo de uma estratégia robusta, por meio da } \\
\text { identificação de recorrências nos diversos cenários. } \\
\text { Advirta-se que cada um dos procedimentos adotados tem, } \\
\text { evidentemente, vantagens e desvantagens, e a escolha se faz tomando-se em } \\
\text { consideração alguns critérios básicos. } \\
\checkmark \text { Opta-se pela primeira alternativa - cenário mais plausível - quando } \\
\text { entre os cenários algum se destaca por sua plausibilidade e } \\
\text { convergência de interesse por parte dos construtores. } \\
\checkmark \text { A opção pela segunda alternativa - visão de futuro - se dá quando } \\
\text { há uma boa convergência de interesse e de ideologia entre os } \\
\text { construtores. } \\
\checkmark \text { Por fim, adota-se a opção se construir uma estratégia robusta no caso } \\
\text { da confluência de duas situações: as alternativas anteriores serem } \\
\text { pouco recomendáveis e os diversos cenários apresentarem elementos } \\
\text { comuns. }\end{array}$ \\
\hline
\end{tabular}

Fonte: Silva (2016).

Por meio do desenvolvimento e implementação da MCVUAR - Metodologia de Cenários para Viabilidade de Uso de Água Residuária em regiões semiáridas é possível alcançar as seguintes metas e objetivos, a saber:

1. Permitir o envolvimento de uma quantidade considerável de atores sociais e institucionais;

2. Equilibrar, de um lado, a participação dos diversos atores interessados no acesso e uso de águas residuárias, particularmente os membros de comitês de bacia, usuários e governos estaduais, e, de outro lado, uma qualidade técnica, articulando, assim, legitimidade política e consistência técnica;

3. Assegurar o relacionamento, de forma sistêmica, entre dimensões, indicadores e atores envolvidos, enriquecendo a compreensão do sistema de reúso de água, e os principais riscos que envolvem sua evolução;

4. Possibilitar o enunciado de futuros distintos e coerentes, entre atores tão divergentes, em comunhão com o conhecimento dos especialistas;

5. Identificar um conjunto de oportunidades e ameaças comuns aos diversos cenários, atribuindo um caráter novo ao modelo;

\section{POLÊM!CA | LABORẸ}

Polêmica - Revista Eletrônica da Uerj - Rua São Francisco Xavier, 524, $1^{\circ}$ andar bloco D, sl.1001 • Tels.: +55 21 2334-4088/4087 • http://www.e-publicacoes.uerj.br/index.php/polemica/index http://www.labore.uerj.br • laboreuerj@yahoo.com.br 
6. Criar uma base para a elaboração dos programas e projetos, possibilitando uma ação antecipatória às políticas públicas, e um instrumento de monitoramento a ser desenvolvido;

7. Constituir uma referência para a elaboração de futuro plano estadual e de bacia.

\section{Principais contribuições científicas e tecnológicas da metodologia}

A demanda crescente e a complexidade da gestão da água com a finalidade de reúso têm envolvido distintos setores da sociedade, incluindo acadêmicos, políticos, articuladores das classes sociais, organizações e demais usuários potenciais dos recursos naturais. Contudo, advirta-se que a integração desse e outros atores são de fundamental importância na busca de tecnologias, métodos e políticas a serem implementadas no processo de uso sustentável da água, com menores riscos de comprometimentos futuros. Nesse sentido, pode-se afirmar que as inovações tecnológicas e a pesquisa científica são indispensáveis para enfrentar os desafios presentes e do futuro da sociedade quanto à disponibilidade e qualidade dos recursos hídricos. No caso das regiões semiáridas, a situação se agrava com as expectativas crescentes dos efeitos do clima, associados à reduzida disponibilidade, seja quantitativa ou qualitativa, de água superficial e subterrânea.

No sentido de incrementar a disponibilidade, merecem destaque nesta proposta metodológica os incentivos públicos para o uso racional dos recursos hídricos, conservação de água e solo, e adoção de técnicas de reúso de águas de qualidade inferior para a agricultura. Nessa perspectiva, instituições de pesquisa, universidades e cientistas têm-se debruçado sobre tecnologias apropriadas, ao mesmo tempo em que o setor público tem elaborado mecanismos de fomento visando ao desenvolvimento, à aplicação e apropriação, por parte das comunidades usuárias de tais tecnologias, que não produzam impactos ambientais adversos, ao mesmo tempo em que agreguem valor aos recursos hídricos disponíveis. Entretanto, o grande desafio tem sido produzir conhecimento e tecnologias para melhorar a situação atual e proteger os recursos naturais no futuro. Para isso, a pesquisa científica e seus resultados, sistematizados e difundidos, têm importância fundamental. É indispensável nesse contexto que a pesquisa seja um processo contínuo, visto que a tecnologia gerada necessita de ajustes pontuais, em que a presença de técnicos e especialistas é oportuna, não excluindo o apoio à programas de capacitação em todos os níveis, abrangendo técnicos, administradores,

\section{POLÊM!CA $\mid$ LABORE}

Polêmica - Revista Eletrônica da Uerj - Rua São Francisco Xavier, 524, $1^{\circ}$ andar bloco D, sl.1001 • Tels.: +55 $212334-4088$ / 4087 • http://www.e-publicacoes.uerj.br/index.php/polemica/index http://www.labore.uerj.br • laboreuerj@yahoo.com.br 
tomadores de decisão e produtores. Quem tem acesso à informação e pode entendê-la tem a vantagem e oportunidade para selecionar a melhor tecnologia e com isso a possibilidade de redução dos riscos de comprometimento dos recursos e insumos de produção da água residuária.

\section{Considerações finais}

Partindo-se da premissa de que o futuro é uma construção social, os atores sociais devem ocupar uma posição central na construção de cenários hídricos para regiões semiáridas. Por outro lado, o poder da metodologia de cenários decorre da habilidade e da capacidade para a organização lógica de um grande volume de informações e de dados relevantes e diferenciados. Com efeito, a metodologia de cenários precisa de um modelo teórico para assegurar a plausibilidade das hipóteses e analisar a consistência das combinações delas, de modo que a descrição da realidade futura seja fundamentada. Assim, para a construção dos cenários, parte-se de um modelo mental (teoria) que interpreta as variáveis centrais e as interações entre elas como uma redução da complexidade da realidade, como certo entendimento do sistema-objeto de análise e projeção futura.

Contudo, advirta-se que o desafio maior no desenvolvimento de uma visão de futuro de cenário hídrico, seja este "normal”, "otimista” ou "pessimista" está em imaginar mudanças nas tendências e nos paradigmas atuais, já que o objetivo não é prever o futuro, nem desenhar um futuro provável ou desejável, e que os cenários, por serem baseados na tese do indeterminismo, não podem e nem pretendem eliminar a incerteza, predizer o que vai acontecer e oferecer segurança e tranquilidade aos agentes econômicos, políticos e institucionais. Porém, como se trabalham e convivem com a incerteza, os cenários procuram analisar e sistematizar as diversas probabilidades dos eventos e dos processos por meio da exploração dos pontos de mudança e das grandes tendências, de modo que as alternativas mais prováveis sejam antecipadas.

\section{Referências}

ASANO, T. Water from (waste) water - the dependable water resource. Water Science and Technology, v. 45, p. 23-33, IWA Publishing, 2002.

\section{POLÊM!CA | LABORE}

Polêmica - Revista Eletrônica da Uerj - Rua São Francisco Xavier, 524, $1^{\circ}$ andar bloco D, sl.1001 • Tels.: +55 21 2334-4088/4087 • http://www.e-publicacoes.uerj.br/index.php/polemica/index http://www.labore.uerj.br • laboreuerj@yahoo.com.br 
BRASIL. Ministério do Meio Ambiente dos Recursos Hídricos e da Amazônia Legal. Lei n. 9.433: Política Nacional de Recursos Hídricos. Brasília: Secretaria de Recursos Hídricos, 1997. 72p.

CETESB. Reúso da água. São Paulo. SP. Disponível em: <https://cetesb.sp.gov.br/aguasinteriores/informacoes-basicas/tpos-de-agua/reuso-de-agua/>. Acesso em: 04 dez. 2016.

DILLON, P. Water reuse in Australia: current status, projections and research. Proc. Water Re-cycling Australia, Adelaide, p. 99-104, oct., 2000.

FRIEDLER, E. Water reuse an integral part of water resources management: Israel as a case study. Water Policy, v. 3, n. 1, p. 29-39, dez. 2001.

GODET, M.; ROUBELAT, F. Creating the future: The use and misuse of scenarios. Long Range Planning, v. 29, n. 2, p. 164-171, abr. 1996.

HESPANHOL, I. Um novo paradigma para a gestão de recursos hídricos. Estudos Avançados, São Paulo, v. 22 , n. 63, 2008.

HURlimann, A. Community Attitudes to Recycled Water Use: an Urban Australian Case Study - Part 2. The University of Melbourne, Cooperative Research Centre for Water Quality and Treatment, 2008.

HURLIMANN, A. et al. Establishing components of community satisfaction with recycled water use through a structural equation model. Journal of Environmental Management, v. 88, n. 4, p. 1221-1232, oct. 2008.

LIMA, V. L. A. de, Reúso de água para irrigação em zonas áridas. In: irrigação em regiões áridas e semiáridas. Cruz das Almas: UFRB, 2009.

Manejo e sustentabilidade da

MONTE, M. H. M. Water Reuse in Europe. E-Water Official Publication of the European Water Association (EWA). 2007.

PNUMA - Programa das Nações Unidas para Meio Ambiente. Perspectivas do Meio Ambiente Mundial 2002 - Geo.-3 - Passado, Presente e Futuro. Publicado em parceria com o Instituto Brasileiro do Meio Ambiente e dos Recursos Naturais Renováveis - IBAMA e Universidade Livre da Mata Atlântica - UMA. Brasília, 2004. Publications Ltd, Londres, 2000.

RIBEIRO, Wagner da Costa (org.). Conflitos e cooperação pela água na América Latina. São Paulo: Annablume, PPGH, 2013.

SALGOT, M et al. Wastewater reuse and risk: definition of key objectives. Desalination, v. 187. p. 29-40, 2006.

SALGOT, M. Water reclamation, recycling and reuse: implementation issues. Desalination, v. 218, p. 190-197, 2008.

SILVA. Sandra Sereide Ferreira da. Construção de cenários para viabilidade do uso de água residuária como elemento mitigador das implicações da seca no semiárido paraibano. Projeto aprovado em primeiro lugar no PROCESSO SELETIVO PARA BOLSISTA DE PÓS-DOUTORADO CONFORME EDITAL 03/2016 PPGRN - UFCG, 2016.

TUNDISI, José Galizia. Recursos hídricos no futuro: problemas e soluções. Estudos Avançados, São Paulo, n. 63 , a. 22,2008

URKIAGA, A. et al. Development of analysis tools for social, economic and ecological effects of water reuse. Desalination, v. 218, p. 81-91. 2008.

USEPA. Guidelines for Water Reuse. 2004.

\section{POLÊM!CA LABORE}

Polêmica - Revista Eletrônica da Uerj - Rua São Francisco Xavier, 524, $1^{\circ}$ andar bloco D, sl.1001 • Tels.: +55 $212334-4088$ / 4087 • http://www.e-publicacoes.uerj.br/index.php/polemica/index http://www.labore.uerj.br • laboreuerj@yahoo.com.br 
Vargas, M. C. O negócio da água. Riscos e oportunidades das concessões de saneamento à iniciativa privada. São Paulo: Fundação Annablume, 2005.

WORLD WATER COUNCIL - WWC. Triennal 2000-2003. Disponível em <http://www.worldwatercouncil.org/sites/default/files/Official_docs/WWC_Triennial_Report_2000-2003.pdf>. Acesso em: 04 dez. 2016.

Recebido em: 07/02/2018.

Aceito em: 15/06/2018.

\section{POLÊM!CA $\mid$ LABORÉ}

Polêmica - Revista Eletrônica da Uerj - Rua São Francisco Xavier, 524, $1^{\circ}$ andar bloco D, sl.1001 • Tels.: +55 21 2334-4088/4087 • http://www.e-publicacoes.uerj.br/index.php/polemica/index http://www.labore.uerj.br • laboreuerj@yahoo.com.br 